\title{
Fundamental Understanding of Nanoporous Carbons for Energy Application Potentials
}

\author{
Katsumi Kaneko $^{1, \uparrow}$, Miki Arai ${ }^{1}$, Masahiro Yamamoto ${ }^{1}$, Tomonori Ohba ${ }^{1}$, Jun-Ichi Miyamoto ${ }^{1}$, Dong \\ Young Kim ${ }^{1}$, Yousheng Tao ${ }^{1}$, Cheol-Min Yang ${ }^{1}$, Kouki Urita ${ }^{1}$, Toshihiko Fujimori ${ }^{1}$, Hideki Tanaka ${ }^{1}$, \\ Takahiro Ohkubo ${ }^{1}$, Shigenori Utsumi ${ }^{1}$, Yoshiyuki Hattori ${ }^{1}$, Takehisa Konishi ${ }^{1}$, Takashi Fujikawa ${ }^{1}$, \\ Hirofumi Kanoh ${ }^{1}$, Masakao Yudasaka ${ }^{2}$, Kenji Hata ${ }^{3}$, Motoo Yumura ${ }^{3}$, Sumio Iijima ${ }^{2,3,4}$, \\ Hiroyuki Muramatsu ${ }^{5}$, Takuya Hayashi, ${ }^{5}$ Yoong Ahm Kim ${ }^{5}$ and Morinobu Endo ${ }^{3}$ \\ ${ }^{1}$ Department of Chemistry, Graduate School of Science, Chiba University, Yayoi, Chiba, 263-8522, Japan \\ ${ }^{2}$ JST Agency, NEC Corporation, Tsukuba 305-8501, Japan \\ ${ }^{3}$ Department of Materials Science and Engineering, Meijo University, Nagoya 468-8502, Japan \\ ${ }^{4}$ Center for Advanced Carbon Materials, National Institute of Advanced Industrial Science and Technology, Tuskuba, 305-8567, Japan \\ ${ }^{5}$ Department of Electrical and Electronic Engineering, Shinshu University, Nagano, 380-8553, Japan \\ ^e-mail: kaneko@pchem2.s.chiba-u.ac.jp \\ (Received January 23, 2009; Accepted July 27, 2009)
}

\begin{abstract}
The importance of nanopore structures of carbons is shown in terms of interaction potential for various molecules including supercritical gases such as $\mathrm{H}_{2}$ and $\mathrm{CH}_{4}$. The key factors for adsorption of supercritical $\mathrm{H}_{2}$ and $\mathrm{CH}_{4}$ are shown for single wall carbon nanohorn, single wall carbon nanotube, and double wall carbon nanotube. The cluster formation of molecules is a key process for water adsorption on hydrophobic carbon nanopores. The X-ray absorption spectroscopic examination elucidates an explicit dehydration structure of ions confined in carbon nanopores.
\end{abstract}

Keywords : Carbon nanospace, Nanocarbon, Adsorption, Supercritical gas, Dehydration of ions

\section{Introduction}

We have a serious issue on reconstruction of established technologies to less energy consuming and less emissiontechnologies of a better quality. Nanoporous materials have been widely applied to energy, resource, separation, environmental, and medical technologies. In particular, nanoporous carbons which have high electronic conductivity and of which pore size can be tunable are hopeful applicants for creation of environmentally friendly technologies. Recently many nanoporous carbons of excellent properties have been developed, giving a great hope to human society to preserve Earth. Such representatives are carbon nanotube and templated carbon family $[1,2]$.

In this note, characteristics and characterization [3] of nanostructures of single wall carbon nanotube(SWCNT)s, double wall carbon nanotube(DWCNT)s, single wall carbon nanohorn(SWCNH)s are summarized in comparison with those of activated carbon fiber(ACF)s. The relationship between nanopore structures and supercritical $\mathrm{H}_{2}$ and $\mathrm{CH}_{4}$ adsorptivities for the above nanocarbons is given for designing better carbon adsorbents. This is because $\mathrm{H}_{2}$ and $\mathrm{CH}_{4}$ are representative clean fuels which are indispensable to save earth. Nuclear fusion needs ${ }^{3} \mathrm{H}_{2}$ and $\mathrm{D}_{2}$; their highly efficient separation with quantum molecular sieving using SWCNT and SWCNH is given. Finally, nanosolution researches are described, which are deeply associated with electricity storage with supercapacitors.

\section{Adsorptive Properties of Nanocarbons for $\mathrm{H}_{2}$ and $\mathrm{CH}_{4}$}

DWCNT, which consists of two graphene layers, is expected to have some advantages over SWCNT in nanoconfinement effect for molecules. Recently, Endo et al. synthesized high-purity DWCNT bucky paper [4]. We examined adsorption properties of this valuable DWCNT for supercritical hydrogen [5]. The experimental hydrogen adsorption isotherms at $77 \mathrm{~K}$ was compared with that of SWCNT. The DWCNT showed higher adsorption ability for supercritical hydrogen even in terms of adsorbed $\mathrm{H}_{2}$ per unit mass of the carbon adsorbent. The GCMC simulation showed that the higher adsorption ability of the DWCNT came from the well ordered hexagonal packing structure of the DWCNT having a relatively wide inter tube gap.

The SWCNH particle has nano-sized single wall tube 


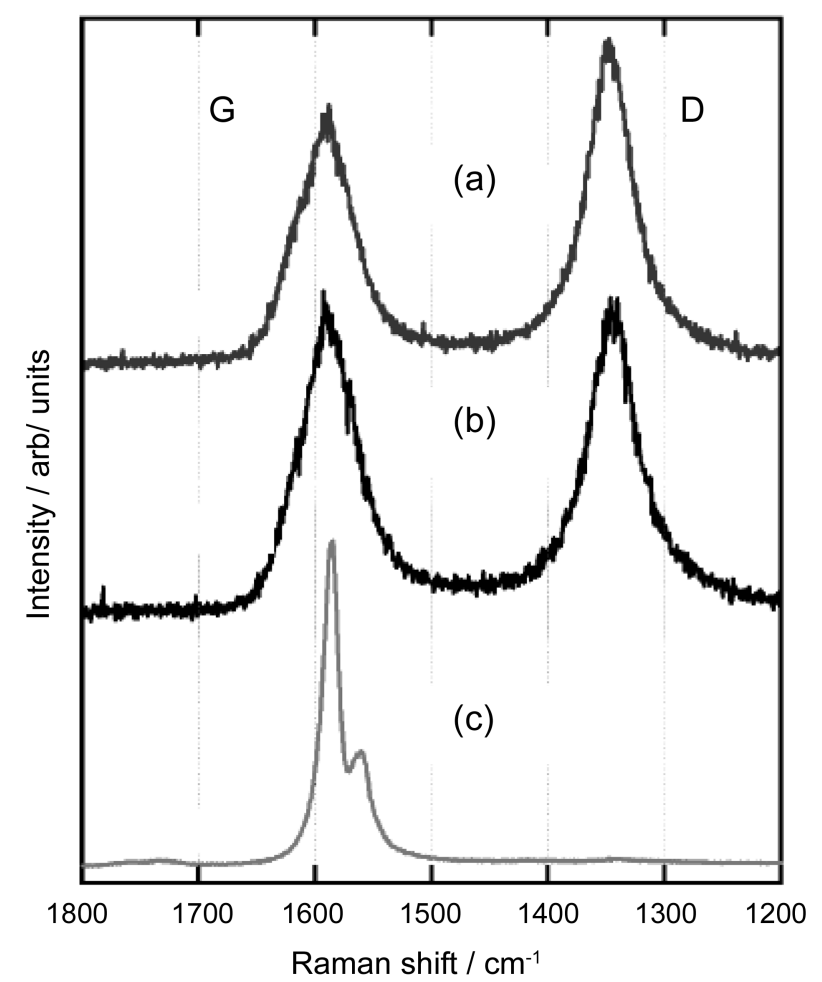

Fig. 1. Raman spectra of single wall carbon nanohorn and single wall carbon nanotube. (a): SWCNH oxidized at $693 \mathrm{~K}$, (b) SWCNH, (c) SWCNT.

structure with closed caps of average cone angle $20^{\circ}$. The diameter of the tubular part of SWCNH is $2 \sim 3 \mathrm{~nm}$ with a length of $30 \sim 50 \mathrm{~nm}$ and the SWCNH particles form a spherical assembly of $80 \mathrm{~nm}$ in diameter. Fig. 1 shows Raman spectra of as-received SWCNH, SWCNH oxidized at $693 \mathrm{~K}$, and SWCNT produced by laser-ablation. Both of SWCNH samples have very broad G- and D-bands, although SWCNT gives only sharp G-band. The Raman spectrum of SWCNH is very similar to that of activated carbon [6]. Thus, SWCNH is more defective than SWCNT, showing n-type semiconductivity for gas adsorption [7]. It was shown that the presence of heptagons and Stone-Wales defects in SWCNH can be directly detected by surface enhanced Raman spectroscopy [3]. The oxidation gives nanoscale windows on the wall of SWCNH, increasing the internal nanoporosity where molecules can be adsorbed. As SWCNH assemblies are packed each other to increase nanoporosity by compression, adsorption amount of $\mathrm{CH}_{4}$ on the compressed SWCNHs is close to the target value of DOE for application [8]. The acid treatment increases ultramicroporosity of SWCNH assembly to give a larger adsorption amount of supercritical $\mathrm{CH}_{4}$ [9]. The increase of the ultramicroporosity was evidenced by the subtracting pore effect method for $\alpha_{\mathrm{s}}$-plot analysis of $\mathrm{N}_{2}$ adsorption isotherms [10]. The same acid treatment enhanced adsorptivity of SWCNT for supercritical $\mathrm{H}_{2}$ and $\mathrm{CH}_{4}$ [11]; the acid-treatment increased the supercritical $\mathrm{H}_{2}$ adsorption amount

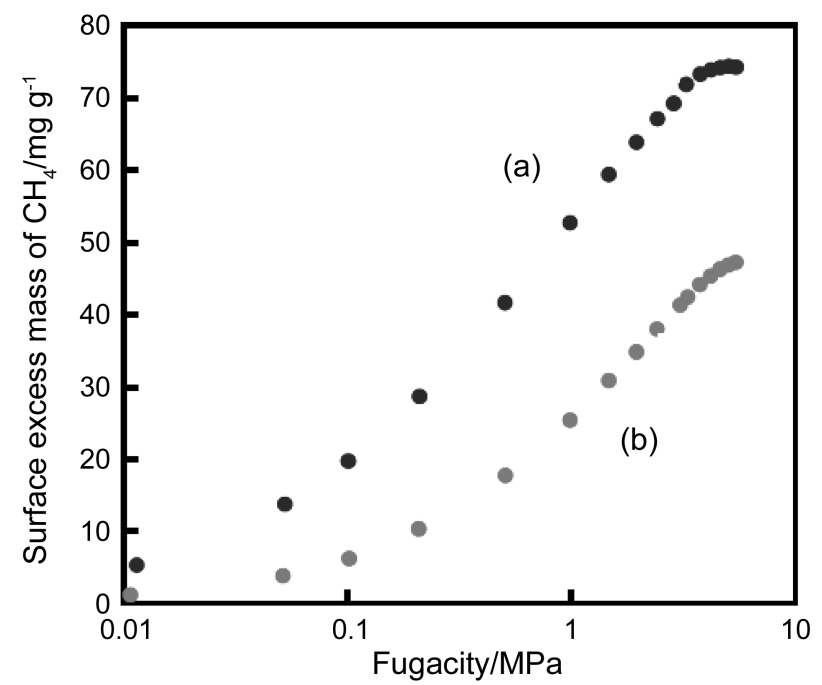

Fig. 2. Adsorption isotherms of methane on SWCNT at $303 \mathrm{~K}$. (a): Acid-treated SWCNT, (b): Non-treated SWCNT.

by more than 3 times. The similar enhancement is observed for $\mathrm{CH}_{4}$ adsorption. Fig. 2 shows high pressure adsorption isotherms of $\mathrm{CH}_{4}$ on SWCNT samples at $303 \mathrm{~K}$. The increment of $\mathrm{CH}_{4}$ adsorption by acid-treatment is about twice, being smaller than that for $\mathrm{H}_{2}$. This is because $\mathrm{CH}_{4}$ can interact with the nanopore of SWCNT more strongly than $\mathrm{H}_{2}$.

When we prepare the bundle structure from mutually isolated SWCNTs using capillary force on drying, SWCNTs form the bundle structure having interstitial ultramicropores. Therefore, we can observe a remarkable enhancement effect for adsorption of supercritical gas, as shown in Fig. 2. Fig. 2 shows high pressure $\mathrm{H}_{2}$ adsorption isotherms at $77 \mathrm{~K}$ for SWCNTs oxidized and dried after immersion in organic solvents (methanol and toluene) [12]. Here, the surface areas from subtracting pore effect method using $\alpha_{s}$-plot are $1230 \mathrm{~m}^{2} / \mathrm{g}$ for non-treated SWCNT, $2270 \mathrm{~m}^{2} / \mathrm{g}$ for oxidized SWCNT, $760 \mathrm{~m}^{2} / \mathrm{g}$ for methanol-treated SWCNT, and 660 $\mathrm{m}^{2} / \mathrm{g}$ for toluene-treated SWCNT. The oxidation treatment removes almost all caps of SWCNTs and thereby the internal pore spaces are available for $\mathrm{H}_{2}$ adsorption. The surface area of $2270 \mathrm{~m}^{2} / \mathrm{g}$ is close to the surface area of graphene $\left(2630 \mathrm{~m}^{2} / \mathrm{g}\right)$; both of external and internal tube walls are exposed to gaseous molecules. Then, oxidized SWCNT gives the greatest adsorption amount of $\mathrm{H}_{2}$. The bundle formation with the aid of the capillary force hides the external surface, giving a half surface area of non-treated SWCNT $\left(1230 \mathrm{~m}^{2} / \mathrm{g}\right)$. However, the $\mathrm{H}_{2}$ adsorption amounts of the methanol- and toluenetreated SWCNTs are almost comparable to that of nontreated SWCNT. This indicates the remarkable increase of ultramicropores by the solvent-treatment. We need to evaluate the exact ultramicroporosity of all SWCNT samples for better understanding of the enhancement mechanism. Also the pillaring of polynuclear aromatic compounds and $\mathrm{C}_{60}$ in the SWCNT bundles is effective to increase adsorptivity 


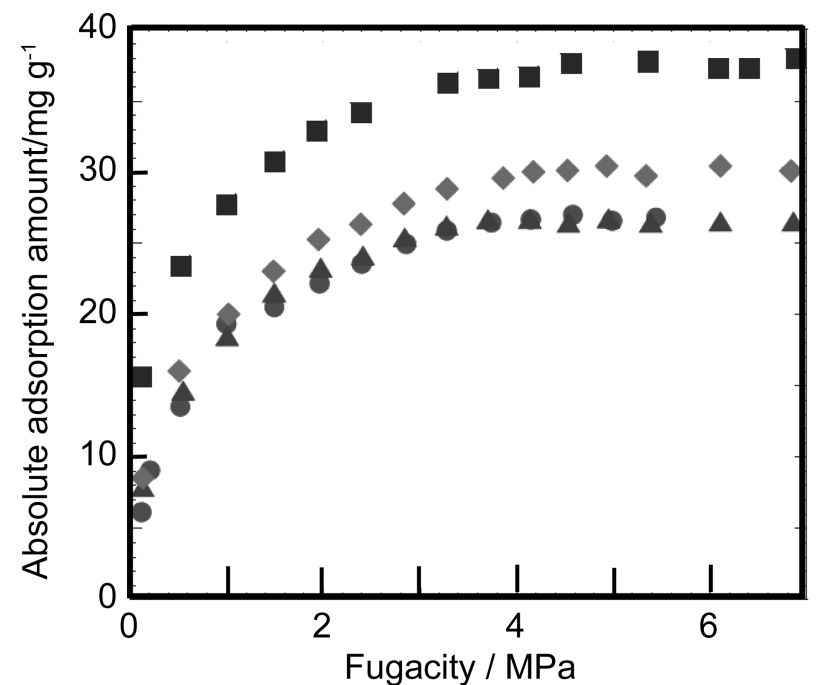

Fig. 3. High pressure $\mathrm{H}_{2}$ adsorption isotherms of SWCNT samples at $77 \mathrm{~K}$. : Non-treated SWCNT, $\boldsymbol{\square}$ : Oxidized SWCNT, $\diamond$ : Methanol-treated SWCNT, $\Delta$ : Toluene-treated SWCNT.

of $\mathrm{H}_{2}$ [13]. In case of $\mathrm{I}_{2}$-adsorption treatment, interstitial ultramicropores in the SWCNT bundles are blocked by $\mathrm{I}_{2}$ molecules, reducing $\mathrm{H}_{2}$ adsorptivity [14]. Also quantum sieving effect of SWCNHs for $\mathrm{H}_{2}$ and $\mathrm{D}_{2}$ was evidenced using low temperature adsorption and molecular simulation [15]. The adsorption amount of $\mathrm{D}_{2}$ is larger than that of $\mathrm{H}_{2}$ on SWCNH at $77 \mathrm{~K}$ by about $7 \%$; the difference becomes larger with lowering the measuring temperature. The clear quantum effect was also observed for activated carbon fiber (ACF)s [16].

\section{Water Adsorption and Dehydrated Structure of Ions Confined in Carbon Nanopores}

Carbon materials are hydrophobic and thereby aromatic molecules interact strongly with SWCNT, inducing a remarkable Raman spectral change [17]. On the contrary, water molecules interact with carbon nanopores very weakly; the adsorption of water vapor does not occur in the low relative pressure region. However, water vapors can be adsorbed on hydrophobic nanoporous carbons above a critical relative pressure $\left(\mathrm{P} / \mathrm{P}_{0}\right)$, as shown in Fig. 4. Fig. 4 shows water vapor adsorption isotherms of pitch-based activated carbon fiber (ACF)s at $303 \mathrm{~K}$. These ACFs were treated in $\mathrm{H}_{2}$ at $1000 \mathrm{~K}$ and $\mathrm{Ar}$ at $1300 \mathrm{~K}$ and their surface oxygen contents are different from each other. The oxygen against carbon atom ratio was determined from X-ray photoelectron spectroscopy. The ratios of nontreated, $\mathrm{H}_{2}-$ treated, and Ar-treated ACFs were 0.07, 0.03 and 0.02, respectively. Water vapor is not adsorbed at a lower relative pressure for three ACF samples, indicating that these ACFs are basically hydrophobic. Adsorption starts around $\mathrm{P} / \mathrm{P}_{0}=0.7$ and water molecules are desorbed around $\mathrm{P} / \mathrm{P}_{0}=0.55$,

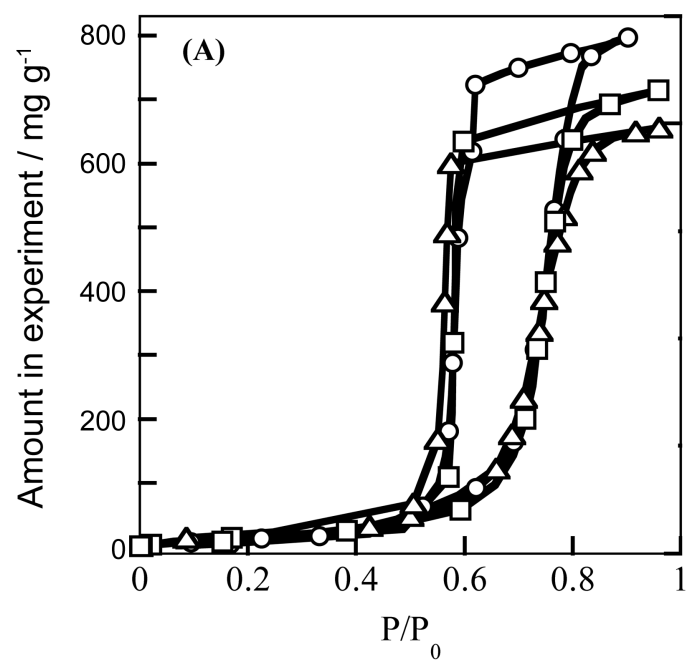

(B)

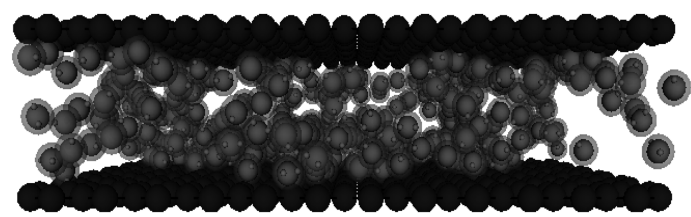

Fig. 4. Water vapor adsorption isotherms of activated carbon fibers having different surface oxygen contents at $303 \mathrm{~K}$ (A) and snapshot of water adsorbed at 0.4 of fractional filling. Oxygen/carbon ratio: $\square ; 0.02, \triangle ; 0.03, \bigcirc ; 0.07$.

showing an explicit hysteresis. This sudden adsorption around $\mathrm{P} / \mathrm{P}_{0}=0.7$ is associated with formation of water molecular clusters which are mainly pentamers to octamers. Fig. 4(B) shows combination structure of the water molecular clusters in the slit-shaped pore. Although the adsorption isotherm is not sensitive to the content of surface oxygen, in situ small angle X-ray scattering shows the fact that the combination structures of clusters for three ACFs are clearly different from each other. Then, information only on the adsorption isotherm cannot provide a correct understanding of water adsorbed in nanopores of carbon [18-20]. It is expected that the adsorption mechanism can be almost applied to water adsorption on nanocarbons. The steep adsorption behavior of water on nanoporous carbon is hopeful to apply to heat-pump. Also understanding of water adsorbed in carbon nanopores can give a designing direction for aqueous solution-type supercapacitor. Very recently we prepared hydrophilicity controlled nanoporous carbons having micropores and mesopores [21].

Ionic solution was confined in hydrophobic carbon nanospaces and the hydration structures of $\mathrm{Rb}^{+}, \mathrm{Cu}^{2+}, \mathrm{Co}^{2+}$, and $\mathrm{Fe}^{3+}$ were determined with EXAFS [22-24] being a powerful tool to determine the coordination number and the bond distance for the nearest neighbor molecules around a target ion. As to $\mathrm{Rb}^{+}$, hydration number and $\mathrm{Rb}-\mathrm{H}_{2} \mathrm{O}$ distance decrease very much by nanoconfinement in the slit-shaped nanospaces of ACF; if we assume that the hydration number in the bulk solution is 6 , the 
hydration number around $\mathrm{Rb}^{+}$is 4.9 for the slit-pore of $1.1 \mathrm{~nm}$ in width. In this case, the bond distance between $\mathrm{Rb}^{+}$and $\mathrm{H}_{2} \mathrm{O}$ also decreases slightly from $0.291 \mathrm{~nm}$ to $0.284 \mathrm{~nm}$ on confinement in the pore. Similar results were obtained for $\mathrm{Cs}^{+}$ and $\mathrm{Sr}^{2+}$. The dehydration of ions by confinement in the nanopores indicates that hydrated ions in the nanopores are smaller than those in the bulk solution. Consequently we can store ions more efficiently in the carbon nanopores.

Transition metal ions have an important role in coordination chemistry. The knowledge on hydration structure around the transition metal ion in the nanopore spaces should extend a new understanding of nature. We observed a remarkable dehydration of $\mathrm{Cu}^{2+}, \mathrm{Ni}^{2+}$ and $\mathrm{Fe}^{3+}$ in carbon nanopores. It is noteworthy that $\mathrm{Fe}^{3+}$ should have a tetrahedral hydration structure, being completely different from the octahedral structure in the bulk solution. Accordingly, confinement of transition metal ions in carbon nanopore spaces should induce a new type of coordination reaction. Also intensive dehydration of $\mathrm{Rb}^{+}$was observed in the quasi one-dimensional nanopore of SWCNHs [24]; the hydration number of $\mathrm{Rb}^{+}$decreases from 6 in the bulk solution to 2.6 in the nanopore spaces of SWCNH. A more serious confinement in the smaller nanopores enhances the dehydration of ions. As SWCNH has the unique nanopore structure, capacitance measurements on SWCNH was carried out. Open SWCNH has nanowindows on the wall whose size is about $0.8 \mathrm{~nm}$. The size is smaller than ordinary organic electrolytes and then a great capacitance increase by addition of the nanowindows was observed only for $\mathrm{H}_{2} \mathrm{SO}_{4}$ /water system [25].

\section{Conclusion}

Although nanoporous carbon materials have intensive potentials for application to sustainable technologies, fundamental understanding of interfacial properties on the nanoporous carbon materials is still insufficient. In particular, we need to establish the ultramicropore control for storage of $\mathrm{CH}_{4}$ and $\mathrm{H}_{2}$ and to understand the electrical double layer structure confined in the nanoscale pore spaces for development of excellent supercapacitor devices.

\section{Acknowledgement}

This work was supported by the Grants-in-Aid for Scientific Research (S) (No. 15101003) by Japan Society of the Promotion of Science and NEDO projects on the Evaluation of Hydrogen Storage on Nanocarbons in Japan.

\section{References}

[1] "Carbon Nanotube", ed. Jorio, A.; Dresselhaous, M. S.; Dresselhaus, G., Springer, Berlin, 2008.
[2] Darmstadt, H.; Ryoo, R. "Adsorption by Carbons" ed. Bottani, E. J.; Tascon, J. M.D. Elsevier, Amsterdam, 2008, Chap. 18.

[3] Fujimori, T.; Urita, K.; Aoki, Y.; Kanoh, H.; Ohba, T.; Yudasaka, M.; Iijima, S.; Kaneko, K. J. Phys. Chem. C. 2008, 112, 7552 .

[4] Endo, M.; Muramatsu, H.; Hayashi, T.; Kim, Y. A.; Terrones, M.; Dresselhaus, M. S. Nature, 2005, 43, 476.

[5] Miyamoto, J.; Hattori, Y.; Noguchi, D.; Tanaka, H.; Ohba, T.; Utsumi, S; Kanoh, H.; Kim Y. A.; Muramatsu, H.; Hayashi, T; Endo,. M.; Kaneko, K. J. Am. Chem. Soc., 2006, 128, 12636.

[6] Utsumi, S.; Miyawaki, J.; Tanaka, H.; Itoi, T.; Ichikuni, N.; Kanoh, H.; Yudasaka, M.; Iijima, S.; Kaneko, K. J. Phys. Chem. B, 2005, 109, 14319.

[7] Urita, K.; Seki, S.; Utsumi, S.; Noguchi, D.; Kanoh, H.; Tanaka. H.; Hattori, Y.; Ochiai, Y.; Aoki, N.; Yudasaka, M.; Iijima, S.; Kaneko, K.; Nano. Lett. 2006, 6, 1325.

[8] Bekyarova, E.; Murata, K.; Yudasaka, M.; Katsuya, D.; Iijima, S.; Tanaka, H.; Kanoh, H.; Kaneko, K. J.Phys. Chem. 2003, 107, 4681.

[9] Yang, C.-M.; Noguchi, H.; Yudasaka, M.; Hashimoto, A.; Iijima, S.; Kaneko, K. Adv. Mater., 2005, 17, 866.

[10] Setoyama, Çm; Suzuki, T.; Kaneko, K., Carbon, 1998, 36, 1459.

[11] Kim, D. Y.; Yang, C.-M.; Noguchi, H.; Yamamoto, M.; Ohba, T.; Kanoh, H.; Kaneko, K. Carbon, 2008, 46, 611.

[12] Yamanoto, M.; Fujimori, T.; Urita, K., Ohba, T.; Kanoh, H.; Hata, K., Yumura, M.; Iijima, S., Kaneko, K. In preparation.

[13] Arai, M.; Utsumi, S.; Kanamaru, M.; Utsumi, S.; Urita, K.; Ohba, T.; Tanaka, H.; Kanoh, H.; Kaneko, K. In preparation.

[14] Hayakawa, C.; Urita, K.; Ohba, T.; Kanoh, H.; Kaneko, K. Langmuir, In press.

[15] Tanaka, H.; Kanoh, H.; Yudasaka, M.; Iijima, S.; Kaneko, K. J. Amer. Chem. Soc., 2005, 127, 7511.

[16] Hattori, Y.; Tanaka, H.; Okino, F.; Touhara, H.; Nakahigashi, Y.; Utsumi, S.; Kanoh, H.; Kaneko, K. J. Phys. Chem. B 2006, 110, 9764.

[17] Gotovac, S.; Honda, H.; Hattori, Y.; Takahashi, K.; Kanoh, H.; Kaneko, K. Nano Lett. 2007, 7 , 583.

[18] Ohba, T.; Kanoh, H.; Kaneko, K. Nano Lett., 2005, 5, 227

[19] Ohba, T.; Kaneko, K. Mol. Phys, 2007, 111, 6207.

[20] Ohba, T.; Kanoh, H.;. Kaneko, K. J. Phys.Chem.C. 2007, $111,6207$.

[21] Tao, Y.; Endo, M.; Kaneko, K. J. Amer. Chem. Soc. In press.

[22] Ohkubo, T.; Konishi, T;. Hattori, Y.; Kanoh, H.; Fujikawa, T.; Kaneko, K. J. Am. Chem. Soc. 2002, 124, 11860.

[23] Tao, Y.; Kanoh, H.; Endo, M.; Konishi, T.; Fujikawa, T.; Kaneko, K. In preparation.

[24] Ohkubo, T.; Hattori, Y.; Kanoh, H.; Konishi, T.; Sakai, H.; Abe, M.; Kasuya, D.; Yudasaka, M ;. Iijima, S.; Fujikawa, T.; Kaneko, K. Physica Scr., 2005, T115, 685.

[25] Yang, C.-M.; Kim, Y.-J.; Endo, M.; Kanoh, H.; Yudasaka, M.; Iijima, S.; Kaneko, K. J. Am. Chem. Soc., 2007, 129, 20. 